\title{
The Effect Of Soluble CD14 Subtype (sCD14ST)/Presepsin And Lactate Clearance On Mortality Status In Pneumonia Patients With Sepsis
}

\author{
Zikanovelia ${ }^{1}$, Ngakan Putu Parsama Putra ${ }^{1}$, Yani Jane Sugiri ${ }^{1}$, Harun Al Rasyid ${ }^{2}$ \\ ${ }^{1}$ Department of Pulmonology and Respiration Medicine, Faculty of Medicine, Universitas Brawijaya/ \\ RSUD Dr. Saiful Anwar, Malang \\ ${ }^{2}$ Department of Department of Public Health Sciences and Preventive Medicine, \\ Faculty of Medicine, Universitas Brawijaya/RSUD Dr. Saiful Anwar, Malang
}

\section{ABSTRACT}

Background: Severe pneumonia accompanied with sepsis could increase death ratio by $7.6 \%$. Lactate clearance is used in assessing the success of early resuscitation in treating sepsis. Presepsin is a biomarker that is sensitive and specific to the bacterial infection that causes sepsis. The purpose of this study was to analyze the effect of presepsin levels and lactate clearance on mortality in pneumonic patients accompanied with sepsis after fourteen day of observation.

Method: Prospective cohort study was done on 42 community acquired pneumonia patients who were admitted to intensive care unit of dr. Saiful Anwar Public Hospital, from March 2019 until May 2019, and were treated following the PDPI guideline. Blood samples were collected on the first, second, and third day of treatment to measure lactate clearance and presepsin levels. Mortality was observed on the $14^{\text {th }}$ day after admittance.

Results: Out of 42 patients, 25 patients lived (59.5\%), and 17 patients died (40.5\%). Logistic regression analysis performed on the presepsin levels on the third day with a cut-off $957 \mathrm{ng} / \mathrm{L}$ had a significant effect on mortality after $14^{\text {th }}$ day $(P=0.034)$. However, presepsin levels on the first day with a cut-off $957 \mathrm{ng} / \mathrm{L}$ had no significant effect on mortality $(P=0.24)$. Likewise, the lactate clearance with cut-off $10 \%$ did not significantly influence the mortality status $(\mathrm{P}=0.136)$.

Conclusion: There is a significant effect between presepsin level on the third day in patient mortality, however lactate clearance and presepsin level assessed on the first day had no significant effect on the mortality after fourteen day of observation.

Keywords: pneumonia, sepsis, presepsin, lactate clearance, mortality

*Correspondence: Zikanovelia - zikanovelia@gmail.com

Submitted: February 4th 2021, Accepted: February 22 th 2021, Published: February $28^{\text {th }} 2021$ 


\section{INTRODUCTION}

Lower respiratory infection is the main cause of death worldwide; one of the lower respiratory tract infections that often occurs is pneumonia. In Indonesia, the prevalence of pneumonia in 2013 reached 4.5\%. ${ }^{1}$ Pneumonia is one of the top 10 causes of hospitalization with a higher Crude Fatality Rate (CFR) of $5.2 \% .^{2}$

Sepsis is a serious health problem and is one of the top ten causes of death in the world. Still, the initial diagnosis of sepsis is often difficult to establish because the clinical presentation of sepsis is very diverse. ${ }^{3}$ Clinical assessment of sepsis can use qSOFA (quick sequential (sepsisrelated) criteria. ${ }^{4}$

Organ Failure Assessment) score to assess the degree of severity of sepsis based on the involvement of the organ failure that occurred. The importance of early detection of sepsis, not only with the clinical parameters where patients often present with severe conditions, but also biochemically as a diagnostic tool and monitoring therapy. ${ }^{4}$

Presepsin or SCD14-ST, has recently been proposed as a biomarker of sepsis. Presepsin was first recognized in 2005 and has become a new important biomarker for the diagnosis and prognosis of sepsis in recent years. ${ }^{5}$

Also, the most widely studied biomarker and the basis for the development of sepsis treatment is lactate levels. In patients with severe sepsis, lactate has a good role in the aspects of diagnosis, initiation of resuscitation, final parameters of resuscitation, and even in determining prognosis. $^{6}$

Researchers are interested in examining presepsin and serum lactate among other sepsis biomarkers because presepsin is a promising new biomarker, is cost-effective and can diagnose precisely and accurately prognostic sepsis, as well as a superior prognostic marker than procalcitonin. Therefore, the investigators are interested in examining the levels of presepsin biomarkers, serum lactate in pneumonia patients with sepsis.

Previous studies about sepsis studies have examined presepsin and lactic acid, but not specific to pneumonia, using Elisa as the average method, however this study specifically foused on pneumonia, and chemiluminescent enzyme immunoassay (CLEIA) was used instead of ELISA to measure presepin levels. This study took 14 days of research, whereas other studies took an average of 30 days. 


\section{METHOD}

This study was conducted using a prospective cohort observational method to determine the relationship between presepsin and lactic acid with the mortality status of pneumonia patients with sepsis who were hospitalized in the intensive care unit. The study was conducted from December 2019 to May 2020 in the Emergency Room and Respiratory High Care Unit/Intensive Care Unit at Dr. Saiful Anwar Malang.

The sample population was community acquired pneumonia patients with sepsis who were hospitalized in the Respiratory High Care Unit/Intensive Care Unit at Dr. Saiful Anwar Malang. According to the formula, the minimum sample size is 40 people. ${ }^{7}$ The Ethical Commitee Medical Reseacrh of Brawijaya University had granted ethical approval for this study.

Patients with community acquired pneumonia are diagnosed from anamnesis, physical examination, CXR, and laboratory examination. Diagnosis are obtained in which the patients shows one of following cases: infiltrate or air brochogram found in CXR and several symptoms, such as cough characteristic change in sputum/purulent sputum, axillar temperature of $\geq 38^{\circ} \mathrm{C}$ or history of fever, chest pain, shortness of breath, physical examination showing signs of consolidation, bronchial breath sound, and rhonki, and leucocyte of $\geq 10,000$ or $<4,500$. $^{1}$

Criterias of sepsis applied to subjects are following the sepsis guideline. In 2016, the Sepsis-3 Task Force updated previous recommendations primarily aiming to accurately differentiate between sepsis and uncomplicated infection. By applying a data-driven approach to identify patients at risk of worse outcomes, the Task Force proposed a new clinical definition, removing the need for systemic inflammatory response syndrome (SIRS) criteria. Thus, in infected patients, sepsis was clinically defined by an increase in Sequential (Sepsis-related) Organ Failure Assessment (SOFA) score of two points or more. Additionally, a bedside score for risk stratification, namely the quick SOFA (qSOFA), has been proposed, which incorporates hypotension, altered mental status, and tachypnea. ${ }^{4}$

Samples were obtained using consecutive sampling in pneumonia patients with sepsis who were hospitalized in the intensive room at Dr. Saiful Anwar Malang who met the inclusion and exclusion criteria. The inclusion criteria in this study were pneumonia patients with sepsis who 
were hospitalized in the intensive room at Dr. Saiful Anwar Malang who is $\geq 18$ years old and the patient and/or his family are willing to take part in the research and sign an "informed consent". Patients with HIV-AIDS, pregnancy, CKD st III, chronic liver disease, and pneumonia patients with sepsis who died before the third day of hospitalization were not included in this study.

Forty-two patients who met the inclusion and exclusion criteria and signed informed consent were measured the levels of lactate clearance on the first and second day of hospitalization, presepsin levels on the first and third day of hospitalization, and observed patient mortality on the fourteenth-day hospital treatment. Patients were treated following the PDPI guideline, wherein patient's treatments were adjusted to patient's conditions. The subjects were either given antibiotics to drink at home, hospitalized, or subjected to intensive care unit. ${ }^{1}$

Processing and data analysis using IBM SPSS version 24.0 software. To see the relationship between lactate clearance, perceptions of $\mathrm{H} 1$ and $\mathrm{H} 3$ with patient status, the Chi-square correlation test was used. To see the effect of lactate clearance, perception of $\mathrm{H} 1$ and $\mathrm{H} 3$ on mortality in pneumonia patients with sepsis, a logistic regression test was used.

\section{RESULT}

Based on the recapitulation of the basic data of research subjects, it was found that the research subjects were more male; namely 23 people (55\%) than 19 women (45\%), aged between 23 to 91 years with the largest age distribution between 57 and 73 years, that is 19 patients or $45 \%$.

Of the 42 study subjects, there were 39 study subjects (93\%) who had comorbid diseases, whereas comorbid diseases did not accompany only 3 patients (7\%). Of the 39 patients who had comorbid, 22 patients survived, and 17 patients died. A total of 3 patients without comorbid disease survived the 14-day evaluation. From Figure 1, it can be seen that there are various comorbid diseases.

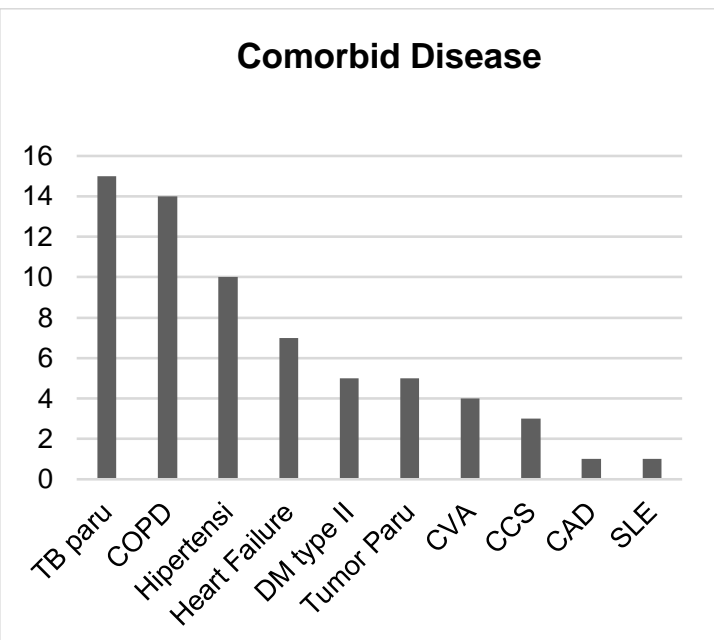

Figure 1. Characteristics Based on Cormobid Diseases 
Table 1. Characteristics of Research Subjects

\begin{tabular}{|c|c|c|c|}
\hline Characteristics & Alive $(n=25)$ & Died $(n=17)$ & Total $(n=42)$ \\
\hline \multicolumn{4}{|l|}{ Gender } \\
\hline Male & $16(38 \%)$ & $7(17 \%)$ & $23(55 \%)$ \\
\hline Female & $9(21 \%)$ & $10(24 \%)$ & $19(45 \%)$ \\
\hline \multicolumn{4}{|l|}{ Age (years) } \\
\hline $23-39$ & $2(5 \%)$ & $1(2 \%)$ & $3(7 \%)$ \\
\hline $40-56$ & $6(14 \%)$ & $6(14 \%)$ & $12(29 \%)$ \\
\hline $57-73$ & $11(26 \%)$ & $8(19 \%)$ & $19(45 \%)$ \\
\hline $74-91$ & $6(14 \%)$ & $2(5 \%)$ & $8(19 \%)$ \\
\hline \multicolumn{4}{|l|}{ Marital Status } \\
\hline Married & $25(60 \%)$ & $17(40 \%)$ & $42(100 \%)$ \\
\hline Single & $0(0 \%)$ & $0(0 \%)$ & $0(0 \%)$ \\
\hline \multicolumn{4}{|l|}{ Smoker } \\
\hline Yes & $9(22 \%)$ & $11(26 \%)$ & $20(48 \%)$ \\
\hline No & $16(38 \%)$ & $6(14 \%)$ & $22(52 \%)$ \\
\hline \multicolumn{4}{|l|}{ Education } \\
\hline No School & $1(2 \%)$ & $0(0 \%)$ & $1(2 \%)$ \\
\hline Elementary School & $9(21 \%)$ & $8(19 \%)$ & $17(40 \%)$ \\
\hline Junior High School & $6(14 \%)$ & $4(10 \%)$ & $10(24 \%)$ \\
\hline Senior High School & $7(17 \%)$ & $4(10 \%)$ & $11(27 \%)$ \\
\hline Bachelor & $2(5 \%)$ & $1(2 \%)$ & $3(7 \%)$ \\
\hline \multicolumn{4}{|l|}{ Profession } \\
\hline College Student & $1(2 \%)$ & $0(0 \%)$ & $1(2 \%)$ \\
\hline Laborer & $1(2 \%)$ & $0(0 \%)$ & $1(2 \%)$ \\
\hline Swasta/Private & $12(28 \%)$ & $11(26 \%)$ & $23(55 \%)$ \\
\hline Farmer & $1(2 \%)$ & $2(5 \%)$ & $3(7 \%)$ \\
\hline Housewife & $5(12 \%)$ & $4(10 \%)$ & $9(21 \%)$ \\
\hline Retired & $3(7 \%)$ & $2(5 \%)$ & $5(12 \%)$ \\
\hline \multicolumn{4}{|l|}{ Comorbid } \\
\hline No & $3(7 \%)$ & $0(0 \%)$ & $3(7 \%)$ \\
\hline Yes & $22(52 \%)$ & $17(41 \%)$ & $39(93 \%)$ \\
\hline \multicolumn{4}{|l|}{ Sputum Culture } \\
\hline Germs (+) & $14(33 \%)$ & $12(29 \%)$ & $26(62 \%)$ \\
\hline Germs (-) & $0(0 \%)$ & $0(0 \%)$ & $0(0 \%)$ \\
\hline Sample (-) & $11(26 \%)$ & $5(12 \%)$ & $16(38 \%)$ \\
\hline \multicolumn{4}{|l|}{ Blood Culture } \\
\hline Germs (+) & $4(10 \%)$ & $8(19 \%)$ & $12(29 \%)$ \\
\hline Germs (-) & $21(50 \%)$ & $9(21 \%)$ & $30(71 \%)$ \\
\hline Sample (-) & $0(0 \%)$ & $0(0 \%) 0$ & $0(0 \%)$ \\
\hline
\end{tabular}


Table 3. Chi-Square Analysis

\begin{tabular}{|c|c|c|c|c|c|c|c|}
\hline \multirow{3}{*}{$\begin{array}{c}\text { Variable } \\
\text { Lactate Clearance }\end{array}$} & \multirow{2}{*}{ Cut Off } & \multicolumn{4}{|c|}{ Patient Status } & \multirow{2}{*}{$\begin{array}{c}\text { OR } \\
(95 \% \mathrm{CI})\end{array}$} & \multirow{2}{*}{$\mathbf{P}$} \\
\hline & & \multicolumn{2}{|c|}{ Alive $(n=25)$} & \multicolumn{2}{|c|}{ Dead $(n=17)$} & & \\
\hline & $<10 \%$ & 10 & $24 \%$ & 13 & $31 \%$ & 4,87 & ר0 \\
\hline & $\geq 10 \%$ & 15 & $36 \%$ & 4 & $9 \%$ & $(0,51-0,84)$ & 0,02 \\
\hline \multirow[t]{2}{*}{ Presepsin H1 } & $<957$ & 15 & $36 \%$ & 5 & $12 \%$ & 3.60 & \multirow{2}{*}{0,051} \\
\hline & $\geq 957$ & 10 & $24 \%$ & 12 & $28 \%$ & $(0,48-0,82)$ & \\
\hline \multirow[t]{2}{*}{ Presepsin H3 } & $<957$ & 16 & $38 \%$ & 3 & $7 \%$ & 8,29 & \multirow{2}{*}{0,003} \\
\hline & $\geq 957$ & 9 & $22 \%$ & 14 & $33 \%$ & $(0,57-0,88)$ & \\
\hline
\end{tabular}

After measuring the marker values for lactate clearance and presepsin on the first and third day, the patients were assessed for their mortality status on the fourteenth day. Descriptive analysis of the lactate clearance and preseptin values was carried out; then the data were presented in the form of cross-tabulations as follows Table 2.

Table 2. Descriptive Analysis

\begin{tabular}{lccc}
\hline Biomarker & $\begin{array}{c}\text { Alive } \\
(\mathbf{n = 2 5})\end{array}$ & $\begin{array}{c}\text { Dead } \\
(\mathbf{n = 1 7})\end{array}$ & $\begin{array}{c}\text { Total } \\
(\mathbf{n = 4 2})\end{array}$ \\
\hline $\begin{array}{l}\text { Presepsin H1 } \\
<957\end{array}$ & $15(36 \%)$ & $5(12 \%)$ & $20(48 \%)$ \\
$\geq 957$ & $10(24 \%)$ & $12(28 \%)$ & $22(52 \%)$ \\
Presepsin H3 & & \\
$<957$ & $16(38 \%)$ & $3(7 \%)$ & $19(45 \%)$ \\
$\geq 957$ & $9(21 \%)$ & $14(34 \%)$ & $23(55 \%)$ \\
Lactate Clearance & & \\
$<10$ & $10(24 \%)$ & $13(31 \%)$ & $23(55 \%)$ \\
$\geq 10$ & $15(36 \%)$ & $4(9 \%)$ & $19(45 \%)$ \\
\hline
\end{tabular}

Chi-square analysis was used to see the relationship between lactate clearance, Presepsin day one and day three of the patient's mortality status.
From the results of the chi-square analysis in Table 3.

The results of the analysis of the Lactate clearance examination with the patient's mortality status were seen with the chi-square analysis, and the $P=0.020$. So, it can be concluded that there is a significant relationship between lactate clearance and patient mortality status.

Based on Table 3, it is found that the odds ratio is 4,875 , which means that a lactate clearance $>10 \%$ tends to become a live patient, 4,875 times greater than that of a dead patient. Or it can be said that a lactate clearance of $\geq 10 \%$ tends to be a patient in the live category, and lactate clearance of $<10 \%$ has a tendency to the status of a patient in the dead category.

Analysis of the results of the examination of Presepsin $\mathrm{H} 1$ with the patient's mortality status seen by chisquare analysis obtained $\mathrm{P}=0.051$, the $\mathrm{HO}$ decision was accepted. So it can be concluded that there is an insignificant 
relationship between Presepsin $\mathrm{H} 1$ and patient status.

Based on Table 3, it is found that the odds ratio is 3,600 , which means that Presepsin $\mathrm{H} 1<957 \mathrm{ng} / \mathrm{L}$ tends to live category patients 3,600 times greater than that of dead patients. Or it can be said that Presepsin $\mathrm{H} 1<957$ $\mathrm{ng} / \mathrm{L}$ tends to the patient status in the life category, and Presepsin $\mathrm{H} 1 \geq 957$ $\mathrm{ng} / \mathrm{L}$ has a tendency to the status of the patient in the dead category.

Analysis of the results of the examination of Presepsin $\mathrm{H} 3$ with the patient's mortality status seen by chisquare analysis obtained the $\mathrm{P}=0.003$, the $\mathrm{HO}$ decision is rejected. So it can be concluded that there is a significant relationship between Presepsin H3 and patient status.

Based on Table 3, it is found that the odds ratio is 8,296 , which means that Presepsin H3<957 $\mathrm{ng} / \mathrm{L}$ tends to live category patients 8,296 times greater than the status of patients with a dead category. Or it can be said that Presepsin H3 <957 $\mathrm{ng} / \mathrm{L}$ tends to the patient status in the life category, and
Presepsin H3 $\geq 957 \mathrm{ng} / \mathrm{L}$ has a tendency to the status of the patient in the dead category.

Logistic regression analysis was used to see the effect of lactate clearance, Presepsin on the first and third day of the patient's mortality status. From the logistic regression results in Table 4.

The Lactate clearance variable has 2 categories, namely $\geq 10 \%$ and $<10 \%$. Based on the analysis, it was found the $\mathrm{P}=0.136$ indicating that there was no significant effect of the Lactate clearance variable on the patient's mortality status.

The coefficient obtained for category $1 \quad(<10 \%)$ is positive $(B=1.159)$, and from the beta exponential value of 3.187 , it shows that if the Lactate clearance variable is $<10 \%$, the tendency for the patient status variable in the category of death is 3,187 times greater than the patient status variable in the life category. Uncertain because the effect showed insignificantly.

Table 4. Logistic Regression Analysis Result

\begin{tabular}{lccccc}
\hline \multicolumn{1}{c}{ Variable } & B & Wald & P & OR & Information \\
\hline Lactate clearance & 1.159 & 2.222 & 0.136 & 3.187 & Not Significant \\
Presepsin H1 & 0.880 & 1.337 & 0.248 & 2.410 & Not Significant \\
Presepsin H3 & 1.707 & 4.501 & 0.034 & 5.510 & Significant \\
\hline
\end{tabular}


Presepsin $\mathrm{H} 1$ variable has 2 categories, namely $<957$ and $\geq 957$. Based on the analysis, it was found $\mathrm{P}=0.248$ indicating that there was no significant effect of the Presepsin $\mathrm{H} 1$ variable on the patient status variable. The coefficient obtained for the category of death ( $\geq 957$ ) is positive $(B=0.880)$, and from the beta exponential value of 2.410 , it shows that the Presepsin H1 category is $\geq 957$, the tendency for the patient status variable in the category of death is 2,410 times greater than the variable for the patient's status in the uncertain life category because the effect shows insignificant.

Presepsin $\mathrm{H} 3$ variable has 2 categories, namely $<957$ and $\geq 957$. Based on the analysis, it was found $\mathrm{P}=0.034$ indicating that there was $a$ significant effect of the Presepsin H3 variable on the patient status variable. The coefficient obtained by the category of death ( $\geq 957$ ) is positive $(B=1.707)$, and the beta exponential value of 5,510 shows that if the Presepsin H3 variable category $\geq 95$, the tendency for the patient status variable in the category of death is greater 5,510 times compared to the patient status variable in the life category. Ascertained because the effect showed a significant effect.

\section{DISCUSSION}

This study showed that pneumonia patients studied more male gender compared to women. But the percentage of comparison is only slightly different than of male sufferers compared to women $(55 \%$ versus $45 \%)$. This is in accordance with observational research by Nasir et al. in 2015, showing that the prevalence of pneumonia in Pakistan is more prevalent in men than in women (54\% compared to $46 \%) .{ }^{7}$ The same thing was also shown in a retrospective study of germ patterns at Dr. Saiful Anwar Hospital Malang in 2018, male pneumonia sufferers more than women (58.43\% compared to $41.6 \%$ ). ${ }^{8}$

Men are more likely to suffer from pneumonia than women because it is suspected that men are more often out of the house so that it is more easily contaminated/infected with germs or viruses, and the number of pathogenic substances in the form of cigarettes and others that are consumed more by men. This can lower the body's immune system, making it more susceptible to pneumonia, compared to women who are mostly housewives and usually only at home so rarely exposed to polluted air. ${ }^{9}$

The incidence of pneumonia increases with age, and more than 90\% of deaths from severe pneumonia 
occurring in patients over the age of 70 . In Ramirez et al.'s study in the United States from 2014 to 2016, the prevalence of pneumonia was most prevalent among the $\geq 65$-year-old age group of 2000 per 100,000 inhabitants in the United States. ${ }^{10}$

In this study, the 57-73-year-old age group had the highest prevalence of pneumonia with sepsis. This is also in accordance with research conducted by Azmi et al. in Malaysia, Indonesia, and the Philippines, which shows that the 66-80-year-old age group has the highest prevalence in Indonesia of pneumonia with sepsis. ${ }^{2}$

The prevalence of severe pneumonia accompanied by sepsis, mostly in the age range of elderly $>65$ years, is caused by various factors including the body's weakened immune system with increasing age, has many comorbid factors including chronic obstruction pulmonary disease (COPD), lung cancer, diabetes mellitus, cerebrovascular diseases, heart failure, and others. The manifestations of clinical symptoms experienced are also not typical and cause falls into critical condition and require intensive care in hospital. ${ }^{11}$

The subject of this study also obtained many comorbid diseases/participants. From the 42 patients showed 39 patients had comorbid, and each had more than one comorbid. Only 3 patients have no comorbid at all. From the research data of 3 patients were able to survive until the 14th day of observation. This suggests comorbid factors will aggravate pneumonia with sepsis and tend to increase mortality. The containment of comorbid disease itself can also increase production and decrease lactate cleansing in the body. ${ }^{12,13}$

In this study, three of the most common comorbidities were pulmonary $T B$, COPD, and heart failure. In patients with pulmonary $\mathrm{TB}$, lactate is also produced in response to infections that are the result of anaerobic glycolysis and help kill Mycobacterium tuberculosis intracellularly. COPD also increases lactate levels related to increased respiratory muscles that occur during an acute exacerbation. Lactate is also associated with the inadequate perfusion of tissue that occurs in heart failure. ${ }^{12,13}$

The etiology of pneumonia from the results of sputum culture in this study was most caused by Klebsiella pneumonia as many in as 7 patients, and some others were also caused by gram-negative basil. This is also reinforced from data from several hospitals in Indonesia in 2012 showed that the most common causes of 
community pneumonia in the inpatient room of the sputum material were gram-negative germs such as Klebsiella Pneumonia, Acinetobacter baumanii, Pseudomonas aeuruginosa while gram positives such as Streptococcus pneumonia, Streptococcus viridans were found in small quantities. From germ pattern research data in RSSA in 2018, the results of sputum showed Germ Klebsiella pneumonia was found in 220 sputum samples. ${ }^{1,8}$

The results of germ type data in this study and from the data of various hospitals are slightly different from Infection Diseases of America/American Thoracic Society (IDSA/ATS) data that illustrates that the percentage of germs that cause community pneumonia is greater by gram-positive than gramnegative. This may be due to the research subjects at Dr. Saiful Anwar Hospital Malang, most of them referral patients who have been hospitalized for several days in primary hospitals with severe conditions and referred to RSSA. Possible germs cause can come from germs contained in the treatment place/ICU hospital before or from the Hospital Dr. Saiful Anwar Malang itself.

The percentage of positive blood culture in this study was $28.5 \%$. The same results were also obtained in research conducted by Yana et al. at Hasan Sadikin Hospital in 2017 obtained a percentage of positive blood culture in sepsis patients of $24 \%$. The figure is still low, and this is because the time of blood collection for culture is still >6 hours, and most research subjects have been given antibiotics before taking blood culture.

Lactate clarance examinations are categorized as $<10 \%$ and $\geq 10 \%$. The results of this study showed that lactate clearance with patient mortality status had an insignificant influence. It can be seen from the analysis of logistic regression statistical value is $\mathrm{P}=0.136$.

Research on lactate clearance has been widely done. Some studies have shown that lactate clearance is a significant factor in predicting the death of patients with sepsis. Surviving Sepsis Campaign 1 hour-bundle establishes the first step of resuscitation management in sepsis and sepsis shock patients is to measure lactic levels, in case of an increase in early lactate levels of $\geq 4 \mathrm{mmol} / \mathrm{L}$ is required fluid resuscitation treatment, and it is recommended to measure lactate levels again to assess the therapeutic response. ${ }^{14}$

Although many studies have used lactate clearance as a good marker in estimating a patient's mortality status, Hernandez et al. said there are still doubts and vagueness in their clinical use, related to the definition of 
clearance/cleansing itself is the expenditure of substance/product from blood measured by volume per time ( $\mathrm{ml} /$ minute). Changes in lactate levels occur due to the production and cleansing of the blood through excretion and lactic metabolism. ${ }^{15}$ According to a review of research by Vincent et al. measuring lactic levels of 1-2 hours will provide accurate and clinically accurate data on lactate levels reduction compared to measuring lactate clearance.

The $>10 \%$ lactate clearance cutoff was first proposed by Nguyen et al. based on his research that lactate clearance $>10 \%$ has the ability to predict deaths within 60 days of sepsis patients. Other research was also conducted by Hambali et al. on-sepsis patients treated in RSCM intensive care. This study obtained a higher survival rate in the group of patients with high lactate cleansing compared to the low lactate cleansing group. In other words, patients with low lactate cleansing had a higher risk of death than patients with high lactate cleansing. Based on the analysis of survival rate in the group of patients with high lactate clearance was $60.0 \%$ and in the group of patients with low lactate clearance of $26.7 \%{ }^{16,17}$

Research conducted by Choudary et al. showed lactate clearance $<10 \%$ in the first 24 hours has a sensitivity and specificity of $78.7 \%$ and $72.2 \%$, and it has a positive predictive value of $83.1 \%$. Inability to achieve lactate clearance levels $\geq 10 \%$ is associated with a high risk of death (likelihood ratio $=2.83 ;=, 95 \% \mathrm{CI}=1.82-4.41) .{ }^{18}$

A meta-analysis conducted by Zhang et al. by analyzing various studies in 2014 illustrates that optimal lactate clearance can provide a low mortality rate in sepsis (critically ill) patients in the ICU. Overall sensitivity and specificity values of lactate clearance in predicting death 0.75 (95\% CI=0.58-0.87) and 0.72 (95\% $\mathrm{CI}=0.61-0.80)$. The prognostic lactate clearance ability devoted to sepsis patients in ICU was seen to increase in the meta-analysis research conducted by Zhang et al. namely with sensitivity and specificity of 0.83 ( $95 \% \mathrm{CI}=0.67$ 0.92 ) and 0.67 (95\% CI=0.59-0.75). This prognostic lactate clearance capability is very meaningful for clinical benefit. ${ }^{19}$

Various studies on lactate clearance of patients with sepsis in ICU showed significant results in prognostic ability/survival rate in patients with sepsis treated in ICU. The study conducted by Nguyen et al. evaluated lactate clearance levels on the first day and 72 hours later, then assessed the patient's death at 28 days. In this study, slightly different observation/ 
assessment of patient death is not done on day 28 , but rather on the 14 th day in the acute phase.

Research meta-analysis by Zhang et al., showed many studies are still not homogeneous in determining the cutoff of marker lactate clearance, the study subjects in some studies were also not specific to assess patients with the source of infection in the lungs. Various confounding factors in some studies can also have the potential to obscure the results of the research.

In this study, the study subjects taken were patients who were treated in intensive care and mostly had comorbid disease factors. In one patient, there can be more than one comorbid. The containment of comorbid disease itself can also increase production and decrease lactate cleansing in the body. ${ }^{12,13}$

However, clinical use of lactate clearance is still used today in patients with sepsis and sepsis shock. The increase in lactate levels is a sign of how the clinical outcomes of patients and the rapid and good lactate clearance are widely associated with increased outcome/ survival rate in patients in ICU with critically ill.

$\mathrm{H} 1$ Presepsin examination is categorized $<957$ and $\geq 957$. The results of this chi-square test showed an insignificant relationship between presepsin $\mathrm{H} 1$ and patient mortality status $\quad(P=0.020, \quad O R=3,600, \quad 95 \%$ $\mathrm{CI}=(0.483-0.823)$. According to the logistic regression test, there was no influence between presepsin and patient mortality with a statistical score less than the chi-square value $(1,337<3,841)$.

H3 Presepsin examination is categorized into $<957$ and $\geq 957$. The results of this chi-square test showed a significant relationship between $\mathrm{H} 3$ Presepsin and patient mortality status ( $P=0.003, O R=8,296,95 \% C I=0.576$ 0.888). According to the logistic regression test, the influence between presepsin and mortality of patients with statistical value is greater than the value of chi square $(4,501>3,841)$. Research conducted by Yu et al. in 2017 that evaluated the therapeutic effectiveness and prognosis of presepsin and procalcitonin dynamically within 12 days. The results showed that presepsin has a better relationship with SOFA score compared to procalcitonin. A decrease in high presepsin rates has a significant relationship with survival rates in patients with sepsis. ${ }^{20}$

Presepsin is a biomarker specific to bacterial infections due to the onset of monocyte/macrophage-specific CD14 receptor complex bonds after LPS bonding with CD14. Presepsin also increased in patients with positive 
cultures on microbiological examinations and in inappropriate antibiotic therapy. Therefore, dynamic presepsin monitoring helps to evaluate infections. ${ }^{21}$

Research showing significant presepsin prognostic value in patients with sepsis with sensitivity figures: 7172\%, specificity: 70-86\%, and NPV: 52$71 \% .{ }^{20}$ For cut-off determination there are still many who are not suitable, for example in El Said et al. research, the best prognostic cut-off is at $2100 \mathrm{pg} / \mathrm{ml}$ with a sensitivity of $92 \%$, specificity of $83 \%$ and accuracy of $88 \%$. In this study took a cut-off conducted by Ali et al. where presepsin $\geq 957$ has sensitivity and specificity of $94.7 \%$ and $85.7 \%$ and has a predictive positive value of $90 \%$ in predicting the death of patients with sepsis. $^{22}$

Other studies that show the same thing that in presepsin show a significant relationship with patient mortality. Carpio et al. said that presepsin in the living group had a median value below $600 \mathrm{ng} / \mathrm{L}$ and decreased significantly from the initial score at the 72-hour evaluation. However, in the deceased group, the median score showed high results $>1700 \mathrm{ng} / \mathrm{L}$, and it showed an increase in value at the evaluation 72 hours later. Behnes et al. report that presepsin is useful for viewing the patient's prognosis on the first and third days of treatment. In living patients, presepsin levels were higher on the first day compared to the third day of treatment. Similarly, Carpio et al. said median presepsin levels in patients who survived were higher on the first day than after 72 hours after the day of treatment. ${ }^{23}$

In this study, the presepsin levels of the first day of treatment showed that there was an insignificant relationship and had no effect on the mortality status of the patient. This can be caused by the research subject factor, which is mostly a referral patient from the previous primary hospital to Dr. Saiful Anwar Malang Hospital, which is a tertiary hospital. The patients usually get pneumonia therapy and treatment by the hospital before, so it can affect the value of presepsin on the first day of treatment at RSSA. This may also be related to the relationship of presepsin levels with patient mortality status.

On the third day of treatment pneumonia patients with sepsis who are treated in the RSSA, the intensive room has received therapy according to the guidelines for the management of pneumonia patients with sepsis who are treated in intensive care and performed treatment if there is a comorbid factor. Empirical antibiotic administration 
patterns look at germ patterns in the RSSA intensive room and also make definitive antibiotic adjustments if there have been patient culture results and in accordance with germ resistance to antibiotics. Presepsin levels measured on the third day showed a significant link to the patient's status, and this third-day preceptual rate had an influence on the mortality status of the patients studied.

\section{CONCLUSION}

First-day presepsin levels in pneumonia patients with sepsis have an effect on the mortality status of pneumonia patients with sepsis within 14 days, but this influence is not statistically significant. Third day prespsin levels in pneumonia patients with sepsis have a statistically significant relationship and influence, so it can be used to predict patient the mortality within 14 days in cases of pneumonia with sepsis. Lactate clearance in pneumonia patients with sepsis has a link and influence on mortality status of pneumonia patients with sepsis within 14 days, but this influence is not statistically significant.

\section{REFERENCES}

1. Perhimpunan Dokter Paru Indonesia. Pneumonia Komunitas:
Pedoman Diagnosis Dan Penatalaksanaan Di Indonesia. 2nd ed. Badan Penerbit FKUI; 2014.

2. Azmi S, Aljunid SM, Maimaiti N, et al. Assessing the burden of pneumonia using administrative data from Malaysia, Indonesia, and the Philippines. Int $J$ Infect Dis. 2016;49:87-93.

3. Rudd KE, Kissoon N, Limmathurotsakul Di, et al. The global burden of sepsis: Barriers and potential solutions. Crit Care. 2018;22(1):123305059.

4. Singer $\mathrm{M}$, Deutschman CS, Seymour C, et al. The third international consensus definitions for sepsis and septic shock (sepsis-3). JAMA - J Am Med Assoc. 2016;315(8):801-810.

5. Zhu Y, Li X, Guo P, Chen Y, Li J, Tao $T$. The accuracy assessment of presepsin (sCD14-ST) for mortality prediction in adult patients with sepsis and a headto-head comparison to PCT: A meta-analysis. Ther Clin Risk Manag. 2019;15:741-753.

6. Ryoo SM, Kim WY. Clinical applications of lactate testing in patients with sepsis and septic shock. J Emerg Crit Care Med. 2018;2:14-14.

7. Nasir N, Jamil B, Siddiqui S, Talat 
N, Khan FA, Hussain R. Mortality in sepsis and its relationship with gender. Pakistan J Med Sci. 2015;31(5):1201-1206.

8. Kurniawan $K$, Haris A, Mustofa $Y$, Andreas A. Pola Kuman RSSA Malang Tahun 2018. RS. Saiful Anwar; 2018.

9. Andayani N. Tingkat Mortalitas Dan Prognosis Pasien Pneumonia Komunitas Dengan Sistem Skoring CURB-65 Di Ruang Rawat Inap Paru Rsud Dr. Zainoel Abidin Banda Aceh. J Kedokt Syiah Kuala. 2014;14:14-19.

10. Ramirez JA, Wiemken $T L$, Peyrani $P$, et al. Adults Hospitalized with Pneumonia in the United States: Incidence, Epidemiology, and Mortality. Clin Infect Dis. 2017;65(11):1806-1812.

11. Cacciatore F, Gaudiosi C, Mazzella $F$, et al. Pneumonia and hospitalizations in the elderly. Geriatr Care. 2017;3(1).

12. Zymliński R, Biegus J, Sokolski M, et al. Increased blood lactate is prevalent and identifies poor prognosis in patients with acute heart failure without overt peripheral hypoperfusion. Eur $J$ Heart Fail. 2018;20(6):1011-1018.

13. Gleeson LE, Sheedy FJ, PalssonMcDermott EM, et al. Cutting Edge: Mycobacterium tuberculosis
Induces Aerobic Glycolysis in Human Alveolar Macrophages That Is Required for Control of Intracellular Bacillary Replication. J Immunol. 2016;196(6):24442449.

14. Kalantari A, Rezaie SR. Challenging the one-hour sepsis bundle. West $J$ Emerg Med. 2019;20(2):185-190.

15. Hernandez G, Bellomo R, Bakker J. The ten pitfalls of lactate clearance in sepsis. Intensive Care Med. 2019;45(1):82-85.

16. Nguyen HB, Kuan WS, Batech $M$, et al. Outcome effectiveness of the severe sepsis resuscitation bundle with addition of lactate clearance as a bundle item: A multi-national evaluation. Crit Care. 2011;15(5).

17. Hambali W, Chen LK, Widodo D, Dewiasty E, Pohan HT, Suhendro S. Peran Bersihan Laktat pada Kesintasan Pasien Sepsis Berat. J Penyakit Dalam Indones. 2016;3(1):38.

18. Choudhary R, Sitaraman $S$, Choudhary A. Lactate clearance as the predictor of outcome in pediatric septic shock. J Emergencies, Trauma Shock. 2017;10(2):55-59.

19. Zhang Z, Xu X, Chen K. Lactate clearance as a useful biomarker 
for the prediction of all-cause mortality in critically ill patients: A systematic review study protocol. BMJ Open. 2014;4(5).

20. Yu H, Qi Z, Hang C, Fang Y, Shao $\mathrm{R}$, Li C. Evaluating the value of dynamic procalcitonin and presepsin measurements for patients with severe sepsis. Am J Emerg Med. 2017;35(6):835-841.

21. Masson S, Caironi P, Fanizza C, et al. Circulating presepsin (soluble CD14 subtype) as a marker of host response in patients with severe sepsis or septic shock: data from the multicenter, randomized ALBIOS trial. Intensive Care Med. 2015;41(1):12-20.

22. Ali FT, Ali MAM, Elnakeeb MM, Bendary HNM. Presepsin is an early monitoring biomarker for predicting clinical outcome in patients with sepsis. Clin Chim Acta. 2016;460:93-101.

23. Carpio R, Zapata J, Spanuth E, Hess G. Utility of presepsin (sCD14-ST) as a diagnostic and prognostic marker of sepsis in the emergency department. Clin Chim Acta. 2015;450:169-175. 